بناء وتقنين مقياس لتقييم التتظيم الذاتي للتعلم لدى طلبة كلية التربية البدنية وعلوم الرياضة جامعة بنغازي وكلية الصفوة بجامعة كربلاء

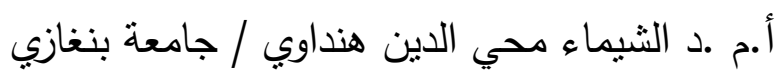

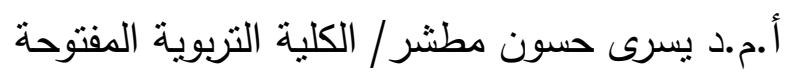

\title{
الماخص
}

أصبح الاهتمام في الآونة الأخيرة بالتتظيم الذاتي للتعلم كمحور أساسي ومهم في عملية التعلم والتعليم لأهميته الكبيرة ودوره الفعال في تعليم الطلبة بطريقة تتظيم معارفهم والمعلومات التي يكتسبوها ذاتيا وتعزيز قوة الطلبة في حل المشكلات التي يوجهونها وهذه العمليات إذا ما تم تعلمها بطريقه صحيحة وإتقانها الطالب فأنها تصبح تلقائية وبمقدور الطالب استخدامها بصوره عفويه والاحتفاظ بها ـ. وهذا ما لاحظتا الباحثتان ان الأمر الذي يؤدي إلى ضعف القدرة على الأداء الجيد لاى الكثبر الطلبة ليس بسبب انخفاض درجة الذكاء أو النقص في الجهد او ضعف المبل للدراسة او إنما بسبب انخفاض مسنوى مهاراتهم في التنظيم الذاتي للتعلم • ويهدف البحث الحالي إلى :

1- بناء وتقنين مقياس لتقييم التتظيم الذاتي للتعلم لدى طلبة كلية التربية البدنية

وعلوم الرياضة بجامعة بنغازي وطلبة كلية الصفوة الجامعة العراق

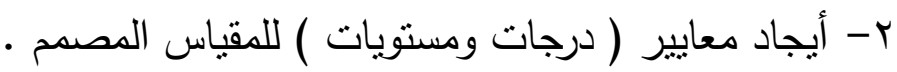

ونم تطبيق علي مجتمع العينة من طلبة كلية التربية البدنية وعلوم الرياضة جامعة بنغازي في مدينة بنغازي بليبيا ،وطلبة كلية الصفوة الجامعة في محافظة كربلاء بالعراق والبالغ عددهم ب7 طالبا حيث تم اخذ مجموعتين من الطلبة من كلا 


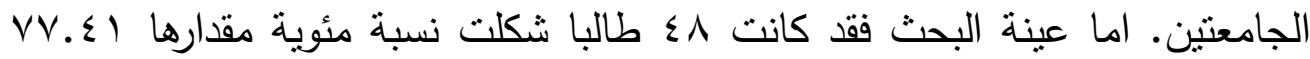

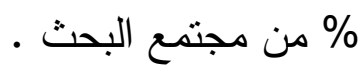

\title{
اما أهم الاستتتاجات : أمات
}

ا- تم التوصل إلى بناء وتقنين مقياس لتقييم التنظيم الذاتي للتعلم لدى طلبة كلية التربية البدنية وعلوم الرياضة بجامعة بنغازي وطلبة كلية الصفوة الجامعة في

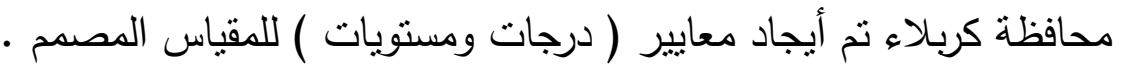
اما اهم التوصيات : ضرورة وضع وحدة تدريبية خاصة للطلبة تضضمن شرح وافي وتطبيقي للتنظيم لما له اثر في حل الكثير من المشكلات .

\begin{abstract}
Interest in the self-regulation of learning has become, in recent times, a fundamental and important axis in the learning and teaching process due to its great importance and effective role in teaching students in a way to organize their knowledge and information that they acquire themselves, and to enhance students' strength in solving the problems they face and these processes, if they are learned in a correct way and the student's mastery, then they become automatic. The student can use it spontaneously and keep it.
\end{abstract}

The current research aims to:

1- Building and codifying a scale for assessing the selforganization of learning among students of the College of 
Physical Education and Sports Sciences at the University of Benghazi and students of the University College in Karbala Governorate.

2- Finding criteria (degrees and levels) for the designed scale.

The application was applied to the sample community of students of the College of Physical Education and Sports Sciences Benghazi University in the city of Benghazi, and the 62 students of the University College in Karbala, where two groups of students were taken from both universities. As for the research sample, it was 48 students, which constituted a percentage of $77.41 \%$ of the research community.

As for the most important conclusions:

1- Building and codifying a scale for assessing the selforganization of learning among students of the College of Physical Education and Sports Sciences at the University of Benghazi and students of the University's Al-Safwa College in Karbala Governorate was reached.

2- Criteria (degrees and levels) were found for the designed scale.

As for the most important recommendations:

The necessity of setting up a special training unit for students that includes a full and practical explanation of the organization because it has an effect in solving many problems. 


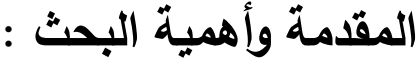

إن معرفة واكتساب الطلبة لعمليات التظظيم الذاتي يعد من الأهداف الرئيسية اللتعليم وفي الوقت نفسه يكون التظظيم الذاتي للتعلم شرطا حيويا للاكتساب الناجح للمعرفة في الددرسة وما بعدها وصولا الى الجامعة والى العمل ولهذا تكمن أهمينها

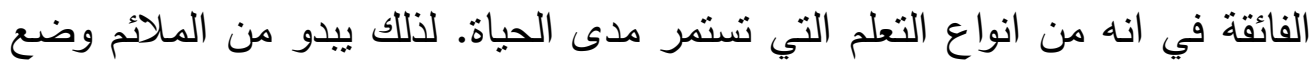

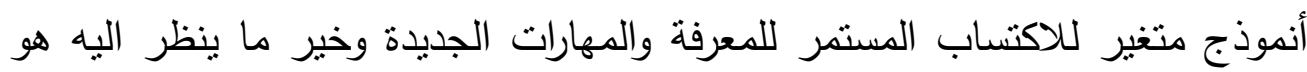

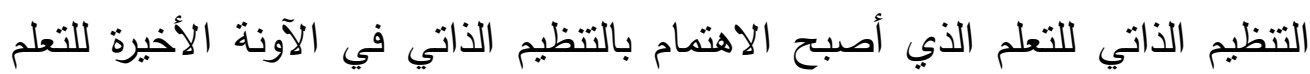

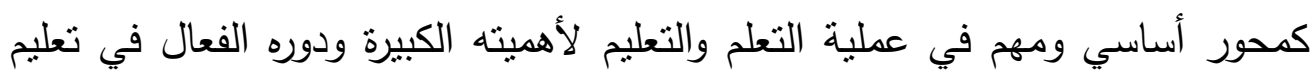
الطلبة بطريقة تنظيم معارفهم والمعلومات التي يكتسبوها ذاتيا وتعزيز قوة الطلبة في حل الشكلات التي يوجهونها وهذه العمليات إذا ما تم تعلمها بطريقه صحيحة وإنقانها

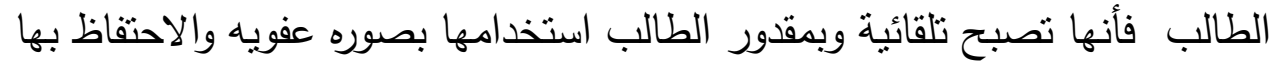

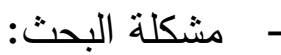

ومن خلال خبرة الباحثنان المتواضعة واطلاعهما على الدراسات والأدبيات التي أكدت ان فثل الكثير من الطلبة في تنظيم المعلومات ومعالجتها في إثناء عملية

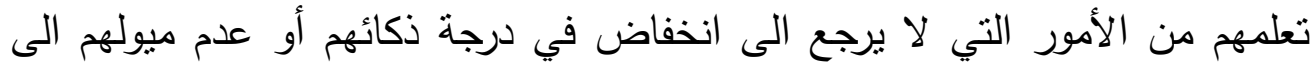

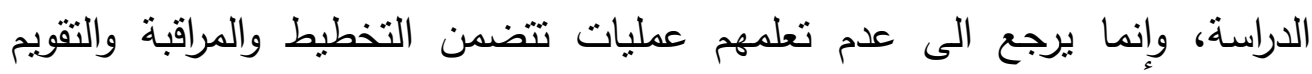
والتحكم في قدراتهم الذاتية، واستثمارها في اداء ما يطلب منهم من إعمال بصوره فعاله

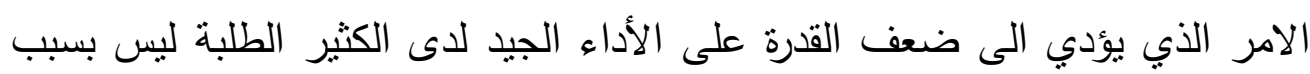

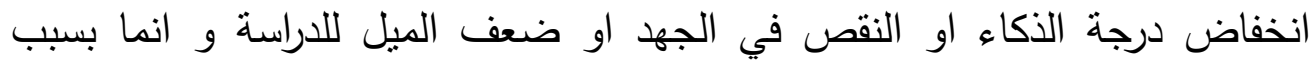
انخفاض مستوى مهاراتهم في التنظيم الذاتي للتعلم . 
() بناء وتقنين مقياس لتقييم التتظيم الذاتي للتعلم لدى طلبة كلية التربية البدنية

وعلوم الرياضة جامعة بنغازي وكلية الصفوة بجامعة كربلاء .

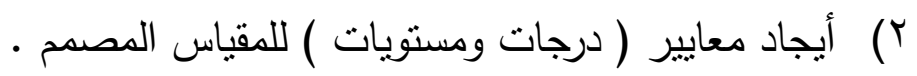

منهج البحث وإجراءاته : استخدمت الباحثتان المنهج الوصفي بأسلوب المسح وذلك لملامته وطبيعة مشكلة الدراسة . لماءعة

مجتمع البحث : قامت الباحثتان بتحديد مجتمع البحث بالطريقة العمدية وهم طلبة

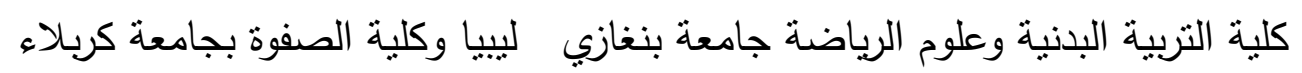

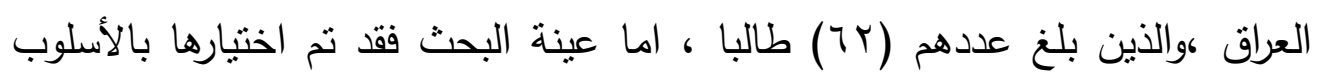
العشوائي البسيط وبلغ عددها (^) طالبا أذ شكلت نسبة مئوية مقدارها ( من المجتمع الأصلي للبحث . وكما مبين في الجدول (1) .

\section{(1) (1)}

يبين إعداد عينة البحث التي تم إجراء الاختبارات عليها وتفاصيلها

\begin{tabular}{|c|c|c|c|c|c|c|c|}
\hline \multicolumn{2}{|c|}{ المجموع الكلي } & \multicolumn{2}{|c|}{ عينة التقنين } & من مبة & الأسسة الن & \multirow{2}{*}{ 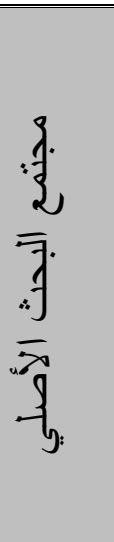 } & \\
\hline 承 & $\overline{7}$ & 牙 & $\overline{7}$ & 司. & ר. & & \\
\hline$\% .87 .09$ & 54 & 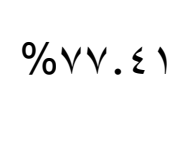 & $4 \wedge$ & 6 & 6 & $7 r$ & طلبة كلية التربية البدنية \\
\hline
\end{tabular}




\section{إجراءات البحث الميدانية :}

بعد الاطلاع على المصادر والمراجع العلمية قامت الباحثثان بعرضها على الخبراء والمختصين (1)، وتم الاتفاق عليها بشكلها الاولي ،حيث بلغت فقرات المقياس • ع فقرة ونسب الاتفاق كانت في جميع الفقرات اكثر من 10 \% ماعدا فقرة واحدة

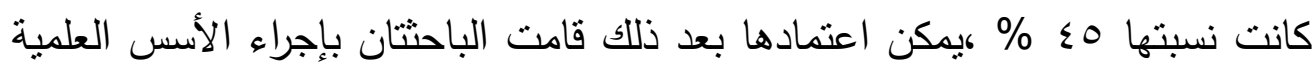
للمقياس.

\section{الجدول ( r )}

\begin{tabular}{|c|c|c|c|}
\hline أرقام الفقرات التي حصلت & \multicolumn{3}{|c|}{ 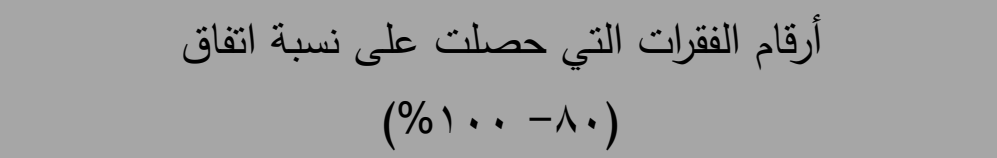 } \\
\hline حذف & دمج & تعديل & لا تحتاج التعديل \\
\hline 7 & - & $\begin{array}{c}411 \\
-11\end{array}$ & 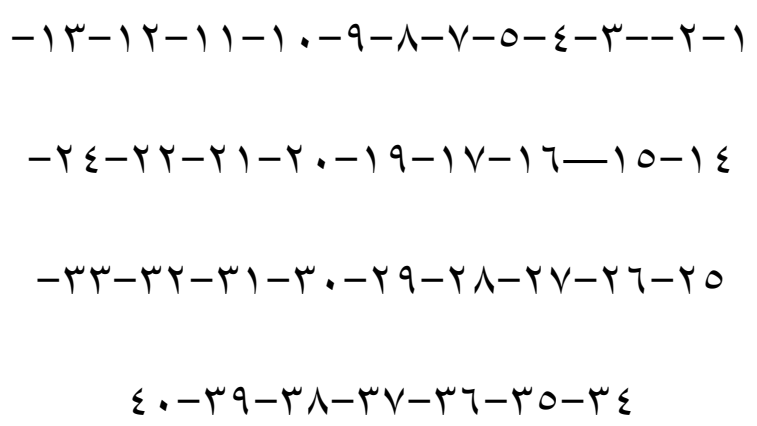 \\
\hline
\end{tabular}

مرفق( ) - (ب) 


\begin{tabular}{|c|c|c|c|}
\hline 1 & $\cdot$ & 7 & $r$ \\
\hline $1 /$ الفقرات المعتمدة / & \multicolumn{3}{|c|}{} \\
\hline
\end{tabular}

يبين نسبة اتفاق الخبراء على فقرات مقياس التتظيم الذاتي للتعلم بهذا أصبح عدد فقرات مقياس التتظيم الذاتي للتعلم بعد التعديل (9 ب) فقرة ، تضمنت r فقرة للتعديل و ا فقرات للحذف و Vr فقرات لا تحتاج التعديل.

\section{الاسس العلمية للمقياس :}

أولا : صدق المقياس Validity : الصدق خاصية أساسية ومهمة في تقويم أية أداة والهدف منه معرفة صلاحية الأداة في قياس الجانب المقصود قياسه وهو قدرة

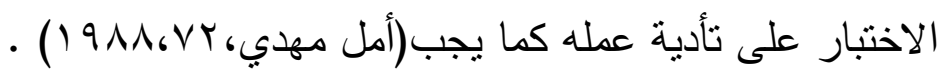
ا: الصدق الظاهري Face Validity : ويعني أن الاختبار قادر على قياس

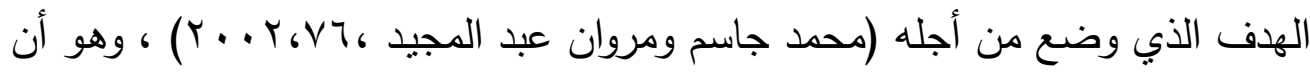
يبدوا الاختبار مقبولا لدى المفحوصين في السمة المقاسة ويتضح هذا النوع من الصدق المبدئي بالنظر إلى الفقرات ومعرفة ما تقيسه ثم مطابقة ذلك بالسمة المراد قياسها فإذا

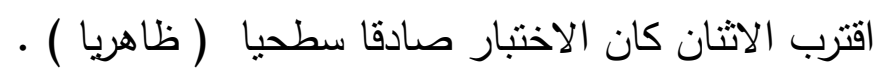

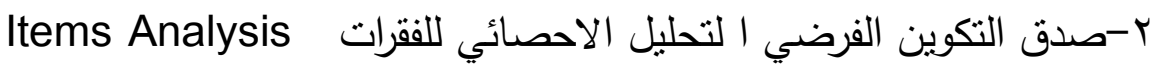
من مواصفات المقياس الجيد هو أجراء عملية التحليل الإحصائي لفقراته لمعرفة قدرة

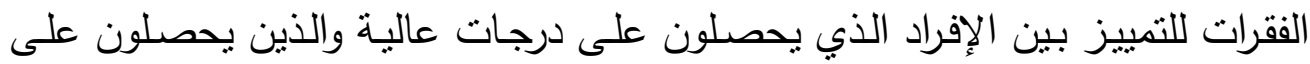
درجــات منخفضـــة فــي المقيــاس نفســـهـ اســتخراج القــوة التمييزيـــة للفقـرات (جابر واحمد، (PowerDiscrimination)

اولاً: اسلوب المجموعات المتطرفة (Contrasted Groups) 
تم استخدام اسلوب المجموعات المنطرفة للكثف عن الفقرات المميزة في مقياس التنظيم الذاتي للتعلم ، اذ اختيرت نسبة ( •\%\%) من الدرجات العليا والدنيا لتمثلا المجموعتين المتطرفتين والجدول التالي يوضح ذلك

$$
\text { جدول (r) (- ) }
$$

قيمة (ت) المحسوبة لفقرات مقياس التنظيم الذاتي للتعلم باستخدام اسلوب المجموعات

المتطرفة

\begin{tabular}{|c|c|c|c|c|c|c|c|}
\hline المحسو & رقم & ت المحسوبة & رقفر & ت المحسوبة & رقفر & ت المحسوبة & رقفر \\
\hline r.. $\Sigma$ & $\begin{array}{r}r \varepsilon \\
-\end{array}$ & r.11 & $-Y r$ & I.r.* & $-1 T$ & r.M & -1 \\
\hline T.VV & $\begin{array}{l}\text { ro } \\
-\end{array}$ & T.YI & $-Y \leq$ & T.99 & $-1 \mu$ & T.M & $-r$ \\
\hline$\Gamma .00$ & $\begin{array}{c}\text { ru } \\
-\end{array}$ & r.v^ & $-r_{0}$ & r.v^ & $-1 \leq$ & T.M & $-r$ \\
\hline$r . \leqslant V$ & $\begin{array}{l}r v \\
-\end{array}$ & 1.99 & $-Y T$ & r.V. & -10 & T.Y & $-\varepsilon$ \\
\hline$r .07$ & rᄉ & T.T & $-Y V$ & T.r & -17 & $r .1 T$ & -0 \\
\hline r.ro & $\begin{array}{l}r q \\
-\end{array}$ & r & $-Y \wedge$ & r.TV & $-1 V$ & $\Gamma .7 \Lambda$ & -7 \\
\hline & & r.o. & $-r q$ & T.rE & -11 & $r .91$ & $-v$ \\
\hline & & r.qu & . & r. 9 . & -19 & r.or & $-\Lambda$ \\
\hline
\end{tabular}




\begin{tabular}{|l|l|l|l|l|l|}
\hline$r . r$ & $-r$ & $r . r r$ & $-r$. & $r . T r$ & -9 \\
\hline$r . I r$ & $-r r$ & $r . V$ & $-r$ & $r .9 \Lambda$ & -1. \\
\hline
\end{tabular}

* ققرة ضعيفة التمبيز

ثانيا :معامل الاتساق الداخلي ( Internal Consistency Coefficient) : تم استخراج معامل الاتساق الداخلي للوصول الى القوة التمبيزية للفقرات اذ ان هذه الطريقة تقدم لنا مقياسا متجانسا في فقراته بحيث تقيس كل فقرة البعد السلوكي نفسه الذي يقيسه المقياس ككل ، فضلا عن قدرتها على ابراز الترابط بين فقرات المقياس.

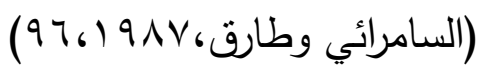

$$
\begin{aligned}
& \text { جدول (؛) }
\end{aligned}
$$

معامل الارتباط بين فقرات المقياس والدرجة الكلية للمقياس

\begin{tabular}{|c|c|c|c|c|c|c|c|}
\hline لن الار & رقم الفقرة & الارتباط & رقفم & معامل & رقفر & المحسد & رقم \\
\hline $\begin{array}{c}0.6 \\
6\end{array}$ & $-r \varepsilon$ & 0.65 & Tr & 0.69 & -14 & 0.69 & -1 \\
\hline $\begin{array}{c}0.6 \\
9\end{array}$ & ס ס & 0.66 & $-Y \varepsilon$ & 0.69 & r & 0.63 & $-r$ \\
\hline $\begin{array}{c}0.6 \\
9\end{array}$ & דומ- & 0.65 & $-r_{0}$ & 0.69 & $-1 \leqslant$ & 0.60 & r \\
\hline 0.6 & -rV & 0.66 & $-Y T$ & 0.60 & -10 & 0.61 & $-\varepsilon$ \\
\hline
\end{tabular}




\begin{tabular}{|c|c|c|c|c|c|c|c|}
\hline 8 & & & & & & & \\
\hline \multirow[t]{7}{*}{$\begin{array}{c}0.6 \\
0\end{array}$} & $-\boldsymbol{H}^{\prime}$ & 0.69 & $-Y V$ & 0.63 & -17 & 0.65 & -0 \\
\hline & & 0.69 & $-r \wedge$ & 0.61 & $-1 \mathrm{~V}$ & 0.66 & -7 \\
\hline & & 0.68 & $-r q$ & 0.62 & -11 & 0.66 & $-V$ \\
\hline & & 0.60 & . & 0.69 & -19 & 0.67 & $-\Lambda$ \\
\hline & & 0.65 & ו & 0.67 & $-r$. & 0.71 & -9 \\
\hline & & 0.66 & - rr & 0.69 & $-Y_{1}$ & 0.65 & -1 \\
\hline & & 0.66 & rr- & 0.62 & $-Y r$ & 0.65 & -11 \\
\hline
\end{tabular}

باستخدام طريقة الاتساق الداخلي ثانياً: الثبات Reliability : وهي صفة يجب توفرها قدر الإمكان في Marshall, J. C)المقياس، ويقصد بها الاقتصاد في نتائج المقاييس

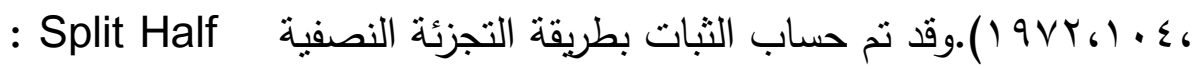
اعتمدت الباحثتان طريقة التجزئة النصفية لأنها من أكثر طرق الثبات ،وتعتمد هذه بهن الطريقة على تقسيم فقرات الاختبار إلى نصفين الأول يحتوي على الفقرات ذات الأرقام الفردية والآخر يحتوي على الفقرات ذات الأرقام الزوجية ، وبذلك تغطي هذه الطريقة درجات منكافئة لنصفي الفقرات) ( فيصل عباس، ک1، 997 ( ) ولحساب الثبات بهذه الطريقة فقد تم استخدام بيانات استمارات بناء المقياس البالغ عددها ( 7 ) استمارة. واستخرج معامل الثبات بين مجموع درجات النصفين باستخدام 
معامل ارتباط سبيرمان (Spearman) ، وقد بلغت قيمة معامل الارتباط بين النصفين

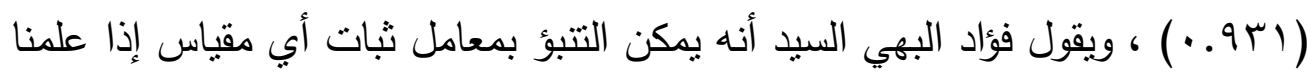

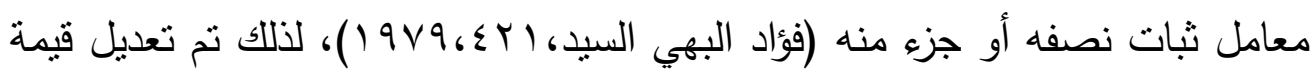
معامل ثبات نصف الاختبار بمعادلة دلالة ثبات سبيرمان بران براون وقد بلغت قيمة معامل الثبات للمقياس ( Spearman - Brawn)

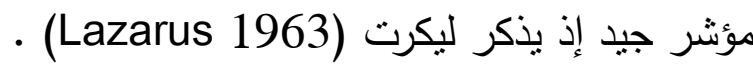
سلم التقدير : وقد حسبت درجة الخارطة الاجتماعية لتعليم الذاتي للطالب من أفراد العينة

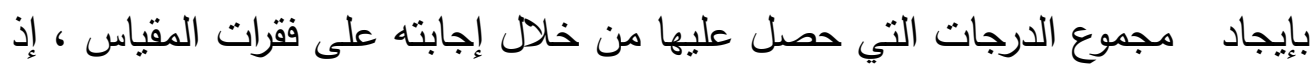
صحح المقياس على أساس ( r^) فقرة بحيث تكون الإجابة عليه وفق مدرج خماسي ، وقد اتبعتا طريقة ( ليكارت Lekart ) في المقياس الحالي فإذا كانت الفقرة بالاتجاه الإيجابي وكانت الإجابة عليه ( دائما ) تعطى ( ) ) درجات لهذه الفقرة وعكسها إذا أجيب عنها ( نادرا ) تعطى ( 1 ( ) درجة لهذه الفقرة و ( r ) درجتين لـ ( أحيانا ) أمّا إذا كانت الفقرة بالاتجاه السلبي وكانت الإجابة عليها ( دائما ) تعطى ( 1 ( ) درجة

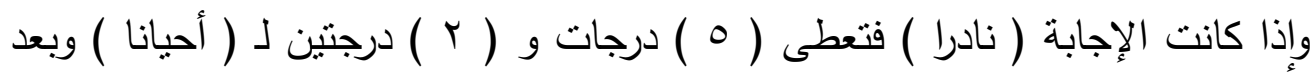
ذللك جمعت درجات البدائل ، حسبما اختارها المستجيب لتكون درجته الكلية على لئ المقياس ، وقد طبقت هذه الطريقة على جميع استمارات عينة البحث والبالغ عددها ( • (

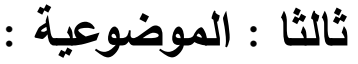

هي عدم نأثنير الأحكام الذاتية من قبل المختبر أو توافر الموضوعية من دون تحيز والتنخل الذاتي من المختبر فكلما زادت درجة الذاتية على الأحكام كلما قلت

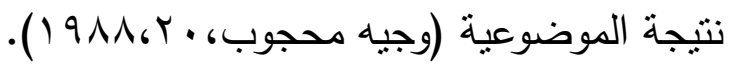
،ع مراعاة تثييت الظروف نفسها وطريقة إجراء تصحيح الاستمارات وفقا لسلم التقدير تم جمع النتائج ومن ثم معاملتها إحصائيا حيث تم احتساب معامل الارتباط البسط مراء 
(بيرسون)وكانت قيم معامل الارتباط عالية وهذا يعني إن الاختبارات جميعها تتمتع بدرجة موضوعية عالية.

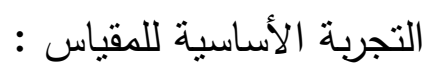

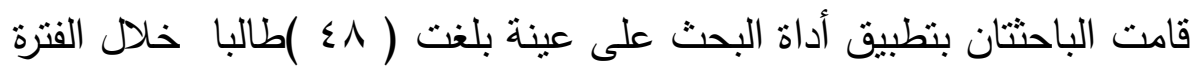

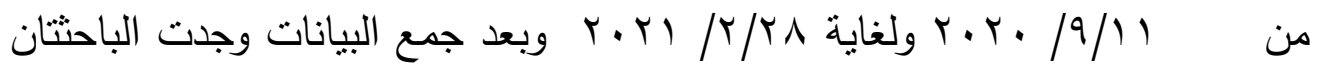

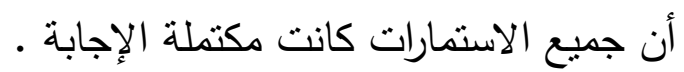

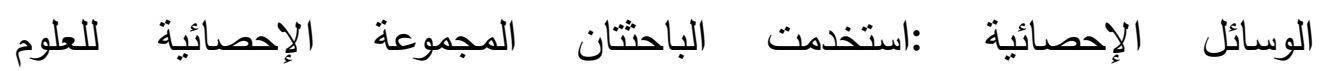
Statistical Package for Social Sciencesالاجتماعية

عرض النتائتج ومناقشتها : جدول (o) يبين الوصف الاحصائي لمقياس التنظيم الذاتي للتعلم

\begin{tabular}{|c|c|c|c|c|c|c|}
\hline ادنى درجة & اعلى & الخطأ & الانحراف & الحسطي & الاحصائيات & ت \\
\hline Tr & $1 \wedge Y$ & $1 \varepsilon .0 \mathrm{~V}$ & $r . . T r$ & 107.0. & مقياس التتظيم الذاتي للتعلم & 1 \\
\hline
\end{tabular}




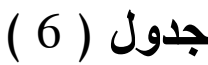

يبين الدرجات المعيارية المعدلة لمقياس التنظيم الذاتي للتعلم

\begin{tabular}{|c|c|c|c|c|c|c|c|}
\hline \multicolumn{8}{|c|}{ الــــــــدرجـــــــــــات } \\
\hline التائية & الزائية & 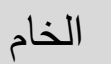 & $ت$ & التائية & الزائية & الخام & ت \\
\hline 50.24 & $. . r-$ & 157 & ry & 38.11 & $1.11-$ & 132 & 1 \\
\hline 50.72 & $\cdots v$ & 158 & rV & 38.60 & $1.11-$ & 133 & r \\
\hline 51.21 &. .14 & 159 & rA & 39.08 & $1 . .9-$ & 134 & r \\
\hline 51.69 &. .17 & 160 & rq & 39.57 & $1 . . \varepsilon-$ & 135 & $\varepsilon$ \\
\hline 52.18 &.$r_{1}$ & 161 & r. & 40.05 & $. .99-$ & 136 & 0 \\
\hline 52.66 & . & 162 & 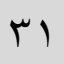 & 40.54 & $.9 \leq-$ & 137 & 7 \\
\hline 53.15 & . & 163 & 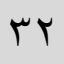 & 41.02 & $. \wedge 9-$ & 138 & V \\
\hline 53.63 & דו". & 164 & 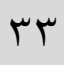 & 41.51 & $\cdot . \wedge \leq-$ & 139 & $\wedge$ \\
\hline 54.12 & $\cdot . \leqslant 1$ & 165 & rs & 41.9 & $\cdot . \Lambda \cdot-$ & 140 & 9 \\
\hline 54.66 & $\cdot . \leqslant 7$ & 166 & ro & 42.48 & $\therefore$. $0-$ & 141 & 1. \\
\hline 55.09 & .0 & 167 & r & 42.96 & $\cdot V \cdot-$ & 142 & 11 \\
\hline 55.57 & .00 & 168 & rV & 43.45 & $.70-$ & 143 & IT \\
\hline 56.09 & .7 & 169 & rᄉ & 43.93 & $.7 .-$ & 144 & r \\
\hline 56.54 & .70 & 170 & $r q$ & 44.66 & . & 145 & $1 \varepsilon$ \\
\hline 57.03 &.$v$. & 171 & $\varepsilon$. & 44.90 & $.0 .-$ & 146 & 10 \\
\hline 57.51 &. Vo & 172 & \&1 & 45.39 &..$\leqslant 7-$ & 147 & 17 \\
\hline 58 &.$\wedge$ & 173 & $\varepsilon r$ & 45.87 & $.(\Sigma)-$ & 148 & iv \\
\hline 58.48 &.$\wedge \varepsilon$ & 174 & $\varepsilon r$ & 46.4 & - דצח. & 149 & 11 \\
\hline
\end{tabular}




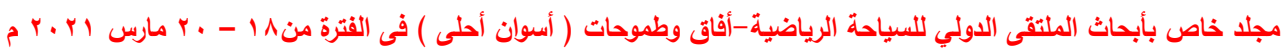

\begin{tabular}{|c|c|c|c|c|c|c|c|}
\hline 58.97 &. .19 & 175 & $\varepsilon \varepsilon$ & 46.84 & . & 150 & 19 \\
\hline 59.45 & $.9 \varepsilon$ & 176 & $\leq 0$ & 47.33 & . YY- & 151 & $r$. \\
\hline 59.94 &. .99 & 177 & $\leqslant 7$ & 47.81 & $\cdot(Y)-$ & 152 & YI \\
\hline 60.42 & $1 . . \varepsilon$ & 178 & $\varepsilon V$ & 48.30 & $.17-$ & 153 & rY \\
\hline 60.91 & 1.99 & 179 & $\varepsilon \wedge$ & 48.78 & $. .1 Y-$ & 154 & rT \\
\hline 61.39 & 1.11 & 180 & $\varepsilon 9$ & 49.27 & $\therefore V-$ & 155 & $r \varepsilon$ \\
\hline 61.88 & 1.11 & 181 & 0. & 50.2 & $\cdot . r-$ & 156 & ro \\
\hline
\end{tabular}

\section{جدول (0)}

يبين الدرجات المعيارية والنسب المقررة لها في منحنى التوزيع الطبيعي والدرجات الخام والدرجات المعيارية وعدد اللاعبين والنسب المئوية المعدلة لمقياس التتظيم الذاتي للتعلم

\begin{tabular}{|c|c|c|c|c|}
\hline المئوية & اللاعبين & الدرجات المعيارية المعدلة & الدرجات الخام & المستويات المعيارية والنسب \\
\hline \% & $\varepsilon$ & 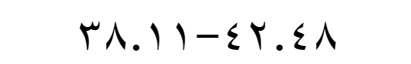 & $132-141$ & 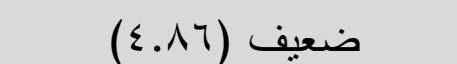 \\
\hline
\end{tabular}




\begin{tabular}{|c|c|c|c|c|}
\hline$\%) \cdot . \leqslant 1$ & 5 & 纟r.96-47.33 & $142-151$ & مقبول (Y.OY) \\
\hline$\% 54.16$ & 27 & $\{V . \Lambda 1-o r . \mid \Lambda$ & $152-161$ & متوسط (97. . ؟) \\
\hline$\% 16.66$ & 8 & Or.TT-OV..r & $162-171$ & جيد (Y乏.OY) \\
\hline$\% 10.41$ & 0 & $0 \vee .01-71.11$ & $172-181$ & جيد جدا (†^.ء ) \\
\hline
\end{tabular}

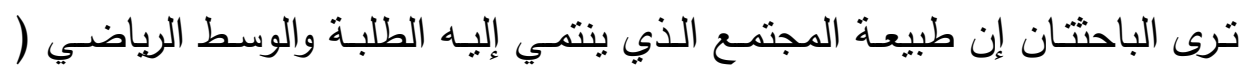

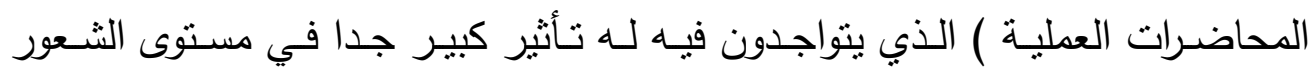
بالتنظيم الذاتي لان الوسط الرياضي والبيئة الرياضية هي بيئة اجتماعية وإنسـانية

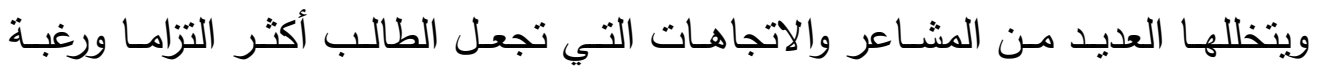

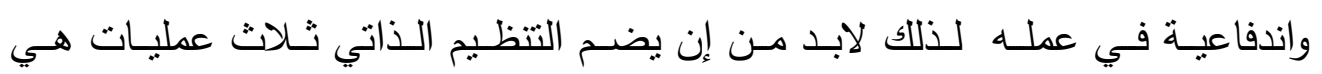

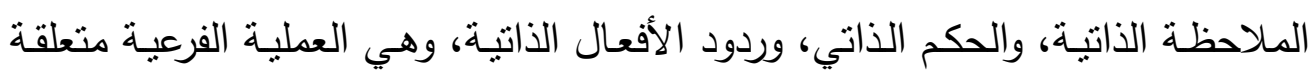
بالأداء، والتي تتفاعل بعضها والبعض الأخر بأسلوب تبادلي مثل الإصغاء إلى شريط وديط (سمعي) لكلام شخص ما عن نفسه (ملاحظة ذاتية)، ونفترض أنها تؤثر في الإحكام الذاتية للتقدم في اكتساب مهارة بلاغية وهذه بدورها إي (الإحكام الذاتية) تحدد الرغبة الإنة اللاحقة للفرد لمواصلة هذه الممارسة التعليمية وهي (رد الفعل الذاتي).

كما تشير الباحثنان إن التنظيم الذاتي يتعلق بسنوات الخبرة والتحصيل العلمي والدورات التدريبية التي لها تأثير كبير جدا على طبيعة تنظيمه الذاتي، فكلما قلت هذه لنه المعـايير الاجتماعيـة فـان الطلبـة سـوف يظهرون التزامـا اقل بمعـايير التنظيم الذاتي وبالتالي سوف تؤثز على نوعية وطبيعة العوامل الثخصية والتي تؤثز تأثنيرا كبيرا على طبيعة وقوة تتظيمه الذاتي للتعلم والعكس صحيح .

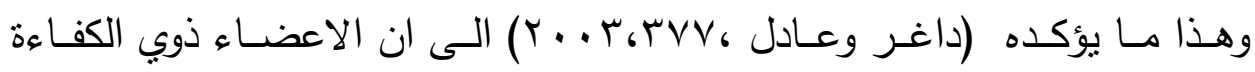
الاجتماعية العالية يظهرون عادة التزام بمعايير الجماعة ومع ذلك فان بعض المتغيرات 
الموقفة قد تؤثر على الإفراد وتقلل من تأثير العوامل الثخصية على تمسكهم بالمعايير الاجتماعية.

وتفسر الباحثتان إن العامل الثخصي والانفعالي والصحي والجسمي لـه تأثيرا

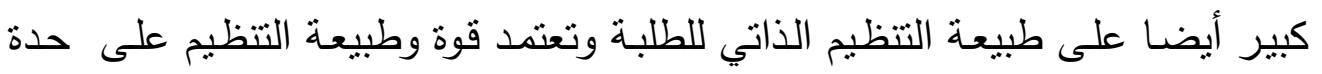

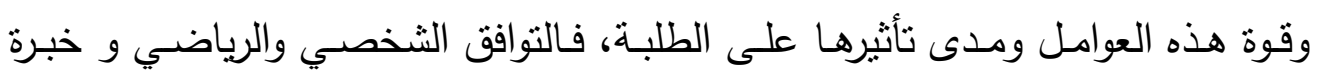
دخول الطالب إلى التدريب داخل المحاضرات العملي من العوامل المهمة في حياته لأنه يتوافق مع أناس آخرين غير أسرته لان الرياضة لها أثرا على صحة الممارس لها لها لها لهات

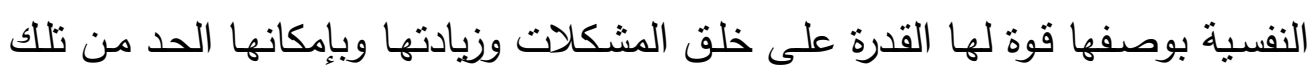
المشكلات وتخفيفها. وتتفق الباحثتان مع مـا اشـار اليه كمال دسوقي ( حينما لا يجد الموقع المناسب في فريقه فان هذا يؤثر على مستواه وقد يدعوه إلى عدم الالتزام بالتدريب والتعلم وبالتالي

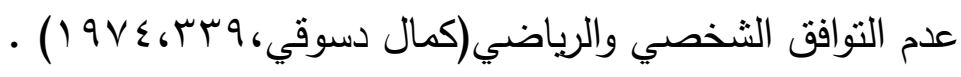

\section{نتائج البحث: :}

ا- نم التوصل الى بناء وتقنين مقياس لتقييم التتظيم الذاتي للتعلم لاى طلبة كلية التربية البدنية وعلوم الرياضة جامعة بنغازي لبييا وطلبة كلية الصفوة الجامعة

$$
\text { في محافظة كربلاء-العراق }
$$

r-نم التوصل الى معرفة مدى تأثير التعليم الذاتي على الطلبة في عملية التعلم.

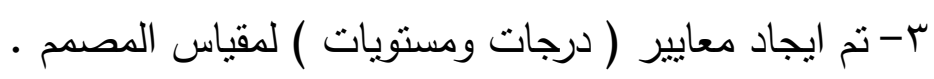

$$
\text { التوصيات : }
$$

1 - اجراء دراسات أخرى وفي نفس موضوع البحث في أنثطة رياضية أخرى . r- ضرورة وضع وحدة تدريبية خاصة للطلبة ت تتضمن شرح وافي وتطبيقي للتنظيم الذاتي للتعلم لما له اثر في حل المشكلات. 
r- استخدام التعليم الذاتي على مختلف التخصصات الدراسية.

$$
\text { أولاًا : المراجع العربية العربية والأجنبية }
$$

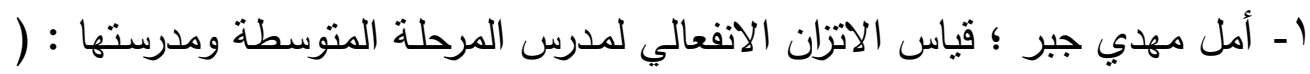

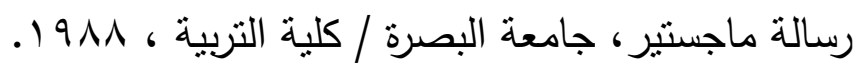

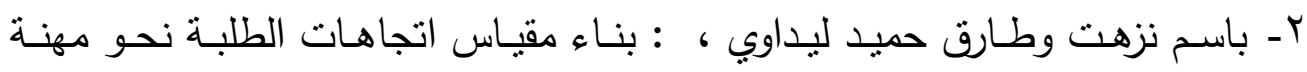

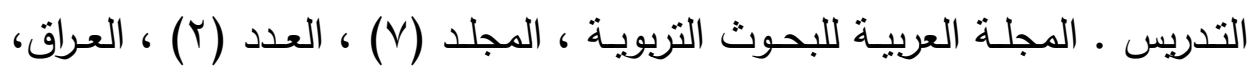

r- جابر عبد الحميد واحمد خيري كاظم، مناهج البحث في التربية وعلم النفس .

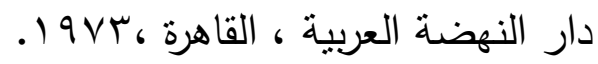

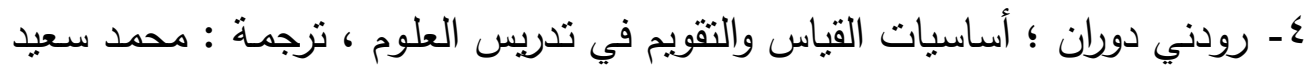

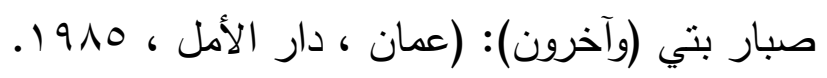

0ـ فؤاد البهي السيد ؛ علم النفس الإحصائي وقياس العقل البشري :القاهرة ، دار الفكر الإن

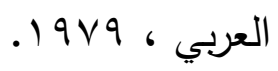

T- فيصل عباس ؛ الاختبارات النفسية ـ تقنياتها وإجراءاتها ، طا بيروت ، دار الفكر

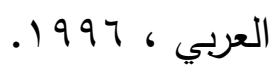

V- محمد جاسم الياسري ومروان عبد المجيد إبراهيم ؛ القياس والتقويم في التربيـة

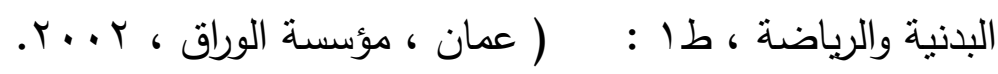

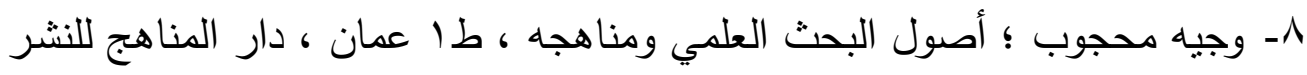

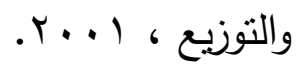

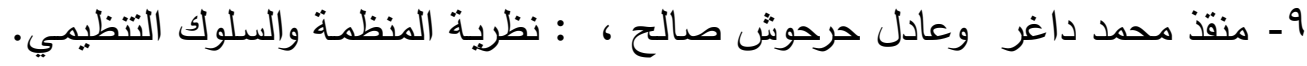

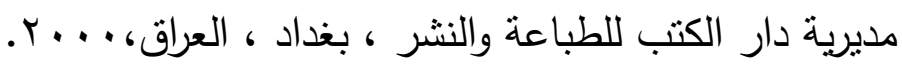


• - محمود عبد القادر محمد علي ؛ التوافق النفسي والاجتماعي للثباب الكويتي

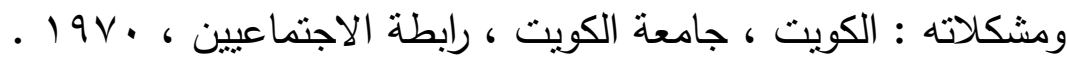

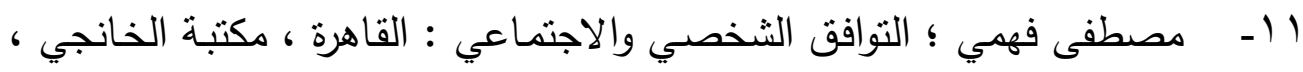

$$
\text { . 619V96 }
$$

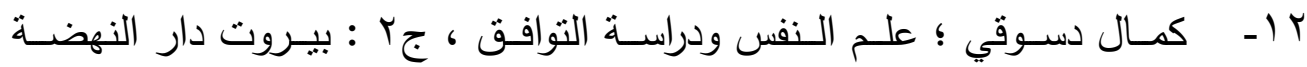

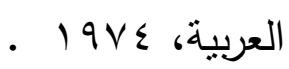

$$
\text { ثنانيا : المراجع الاجنبية : }
$$

1-Marshall, J. C.; Essentials Testing: (California, AddisonWesley, 1972.

\section{مرفق (1) - مرق}

\begin{tabular}{|c|c|c|}
\hline مكان العمل & التخصص & 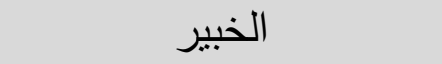 \\
\hline جامعة بنغازي & علم النفس & أ. د عبد الرحيم البدري \\
\hline جامعة ميسان & الاختبارات والقياس & ا.د رحيم عطية جناتي \\
\hline جامعة البصرة & علم النفس & أ.د عبد الكاظم جليل حسان \\
\hline جامعة البصرة & الاختبارات والقياس & ا.د رائد محمد مشتت \\
\hline جامعة البصرة & علم النفس & أ.د عبد الستار جبار الضمد \\
\hline
\end{tabular}

اسـماء الخبراء ( قياس لتنظيم الذاتي للتعطم) 


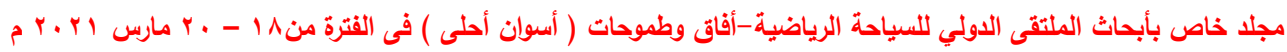
العدد الاول

\begin{tabular}{|c|c|c|}
\hline جامعة البصرة & الاختبارات والقياس & ا.د زينب عبد الرحيم خضير \\
\hline جامعة ميسان & علم النفس & ا.د رحيم حلو علي \\
\hline جامعة بنغازي & علم الاجتماع & ا.د انتصارحمد امبيه \\
\hline جامعة ميسان & علم النفس & ا.م.د علي مطير حميدي \\
\hline
\end{tabular}

\section{المرفق( r )}

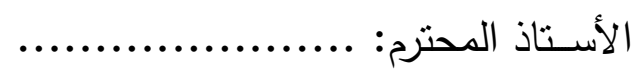

\section{تحية طيبة ،6،6}

$$
\text { تقوم الباحثتان إجراء البحث الموسوم بـ }
$$

(بناء وتقنين مقياس لتقييم التنظيم الذاتي للتعلم لدى طلبة لبنة كلية التربية البدنية وعلوم الرياضة بجامعة بنغازي ـليبيا وطلبة الصفوة الجامعة في محافظة كربلاء في لئي

\section{العراق )}

وليتم تحقيق اهداف البحث قامت الباحثتان بتصميم مقياس التظظيم الذاتي

$$
\text { للتعلم }
$$

ونظراً لما نعهده فيكم من خبرة ودراية وامانة علمية في هذا المجال نرجو ابداء

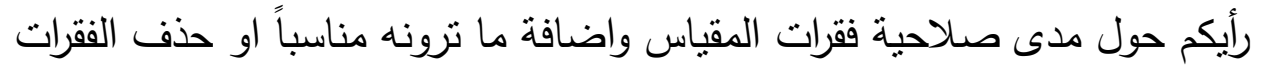

التي تعتقدون انها غير مناسبة مدئ 
نموذج استمارة معدة لمقياس الخريطة الاجتماعية بصورته الأولية ولكم فائق الثكر والتقدير ... الباحثنان

الاستمارة المسعدة الخاصة باستفتاء أراء السادة الخبراء لمقياس الخريطة الاجتماعية

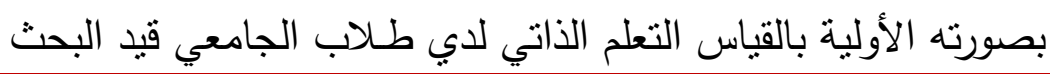

\begin{tabular}{|c|c|c|c|c|c|c|}
\hline | تنطبق & |قلبلة & متوسطة & كبيرة & كبيرة & العبـــــــــــــــارت & $ت$ \\
\hline & & & & & اضع جدول زمنيا لتتظيم وإدارة وقت الدراسة والتزم به قدر الإمكان & 1 \\
\hline & & & & & |بحث عن افضل الحلول لأب مشكلة & r \\
\hline & & & & & اقوم دائما بتسجيل ما يدور في ذهني من افكار في بطاقة ملاحظاتي & r \\
\hline & & & & & |حرص على ترنيب واجباتي على حسب الأولوية & $\varepsilon$ \\
\hline & & & & & | اعمل لمستقبلي وفق خطة رسمتها لنفسي & $\circ$ \\
\hline & & & & & انظم المواد التعليمية بشكل يجعلها سهلة التناول عند الحاجة & 7 \\
\hline & & & & & اضع لنفسي اهداف واقعيه لا تمكن من تحقيها & $\mathrm{v}$ \\
\hline & & & & & | انظم نفسي لكي اذاكر كل المواد المقررة & $\wedge$ \\
\hline & & & & & | استعد للامتحانات قبل موعدها بوقت كافي & 9 \\
\hline & & & & & اخطط قبل تتفيذ أي عمل اقوم به & 1. \\
\hline & & & & & أقوم بإبراز الأفكار والنقاط الهامه اثثاء القراءة وضع الخطوط تحتها & 11 \\
\hline
\end{tabular}




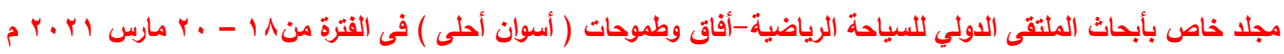

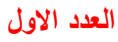

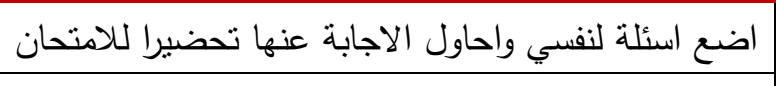

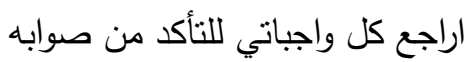

لا اهتم بالملاحظات التي يذكرها المدرس في اثثاء الدرس ولا ادونها

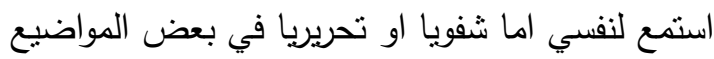
$1 \varepsilon$

10

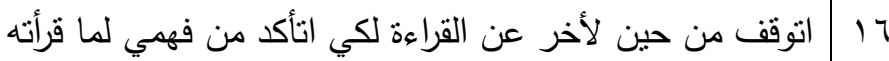

عندما اكمل واجباتي بشكل جيد سوف امارس هوايتي المفضلة بعد الاتتهاء من القراءة اراجع الفصل الذي قرأت من خلاله النقاط البارزة

اقوم بعمل الملخصات للمادة التي اقرأها حتى تكون المراجعة سهله اكتب جميع الافكار المهمة المرنبطة لموضوع الدرس لهن $r$.

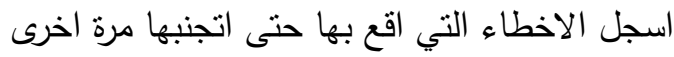
اكافئ نفسي عندما احصل على درجه جيدة في الامتحان غالبا ما اربط بين الخبرة الجديدة

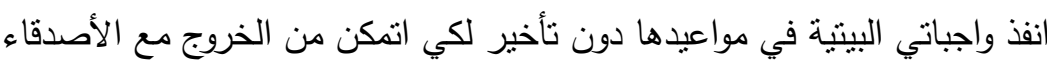

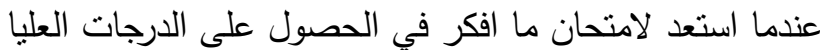

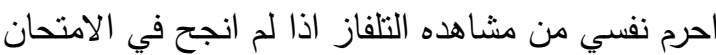
حينما لا احصل على درجه جيده في الامتحان فسوف لن اتصفح الانترنيت

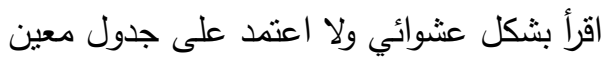
احاول دائما ربط الموضوعات التي اقوم بقراءتها بشي جذاب حتى اتككن من حفظها اعزل نفسي عن الاخرين عندما لا احصل على درجه جيده في الامتحان اجد لدي القدرة على القراءة الواعية والدراسة المستقبلية r) rr $r t$ rร

حينما اقوم بالقراءة لأي موضوع اضع سائله واحاول الاجابة عنها اجد لدي القدرة على اختيار الاساليب المناسبة لدراستي اهتم بمراجعة أي عمل اقوم به لكي أتأكد من صحته اجنه اهتم بمعرفة الاخطاء التي اقع بها اعمل على اعادة ما اتعلمه حتى بعد الامتحان اقوم بتصحيح اخطائي في الاشياء التي مررت بها اهتم بحل الأسئلة في المقررات التي ادرسها 


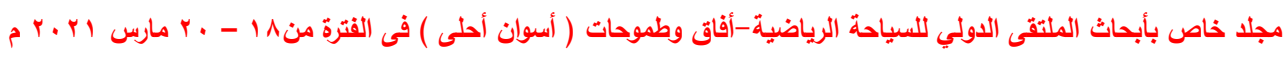
العدد الاول

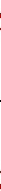




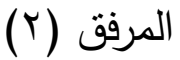

عزيزي الطالب المحترم .. - ع

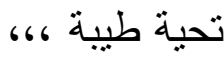

يتضمن هذا المقياس عدد من العبارات التي تمثل الصفات والخصائص التي

تتسم بها التنظيم الذاتي ، وقد وضع امام كل عبارة ميزان متدرج من ( () الى (0) ،

يرجى قراءة كل عبارة وتقدير ما اذا كنت تحمل هذا المفهوم نحو ذاتك ام لا .

تأمل الباحثثان تعاونكم من خلا اجابتكم الصريحة عن جميع عبارات المقياس

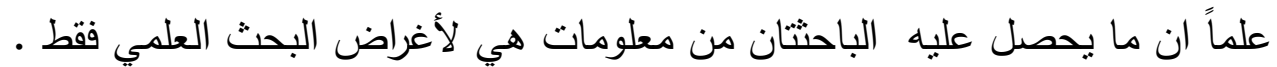

مع فائق الثكر والتقدير • معري

\begin{tabular}{|c|c|c|c|c|c|c|}
\hline تنطبق & بدرجة & متوسطة & كبيرة & كبيرة & العـــــبارات & $ت$ \\
\hline & & & & & به قدر الإمكان جدول زمنياً لتنظيم وإدارة وقت الدراسة والتزم & 1 \\
\hline & & & & & ابحث عن افضل الحلول لأي مشكلة & $r$ \\
\hline & & & & & في بطاقة دائما بتسجيل ما بدور في ذهني من افكار & r \\
\hline & & & & & احرص على ترتيب واجباتي على حسب الأولوية & $\varepsilon$ \\
\hline & & & & & اعمل لمستقبلي وفق خطة رسمتها لنفس & 0 \\
\hline & & & & & اضع لنفسي اهداف واقعيه لا تمكن من تحقيها & 7 \\
\hline & & & & & انظم نفسي لكي اذاكر كل المواد المقرة & V \\
\hline & & & & & استعد للامتحانات قبل موعدها بوقت كافي & $\Lambda$ \\
\hline & & & & & اخطط قبل تتفيذ أي عمل اقوم به & 9 \\
\hline
\end{tabular}




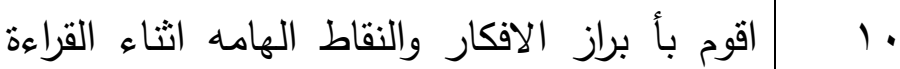
وضع الخطوط تحتها |r| 11

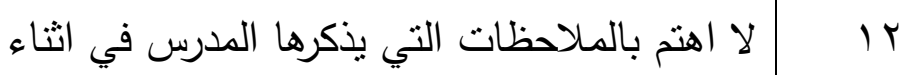
الدرس ولا ادونها

r| اسمع لنفسي اما شفويا او تحريريا في بعض المواضيع

ع ا اتوقف من حين لأخر عن القراءة لكي اتأكد من فهمي لما قرأته

10 10 هوايتي المفضلة

17 17 بعد الانتهاء من القراءة

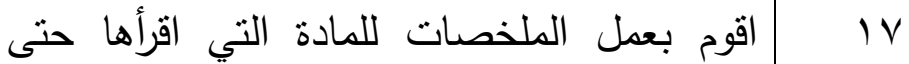
تكون المراجعة سهله

11 اكتب جميع الافكار المهمة المرتبطة لموضوع الدرس

| 19 | اسجل الاخطاء التي اقع بها حتى اتجنبها مرة اخرى

P المافئ نفسي عندما احصل على درجه جيدة في الامتحان

T اقوم بربط معلوماتي السابقة حسب ما املكه من خبرات 
انفذ واجباتي البيتية في مواعيدها دون تأخير لكي اتمكن من الخروج مع الأصدقاء

عندما استعد لامتحان ما افكر في الحصول على

الدرجات العليا

احرم نفسي من مشاهده التلفاز اذا لم انجح في

الامتحان

حينما لا احصل على درجه جيده في الامتحان فسوف لن اتصفح الانترنيت

اقرأ بشكل عشوائي ولا اعتمد على جدول معين

احاول دائما ربط الموضوعات التي اقوم بقراءتها

$$
\text { بشي جذاب حتى اتمكن من حفظها }
$$

اعزل نفسي عن الاخرين عندما لا احصل على

$$
\text { درجه جيده في الامتحان }
$$

اجد لدي القدرة على القراءة الواعية والدراسة

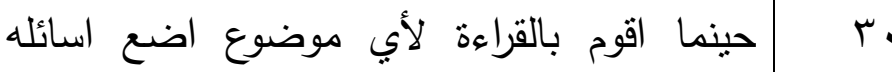
واحاول الاجابة عنها

اجد لدي القدرة على اختيار الاساليب المناسبة

اهتم بمراجعة أي عمل اقوم به لكي أتأكد من لنا صحته

اهتم بمعرفة الأخـــــــاء التي اقع بها 


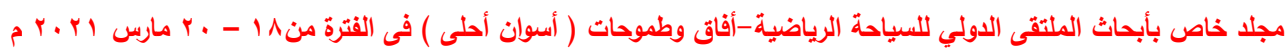
العدد الاول

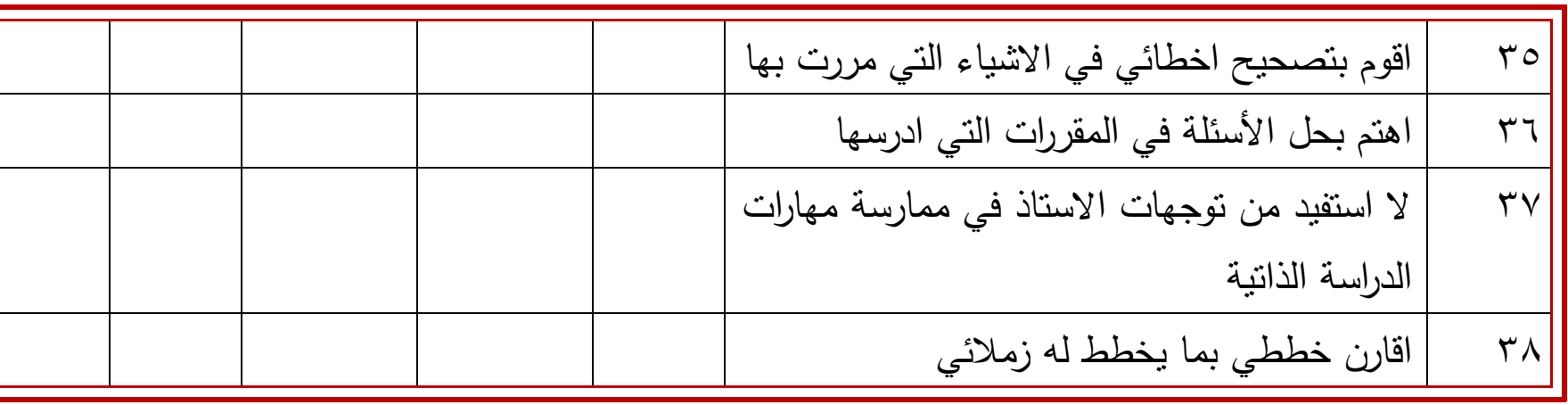

